\title{
Análise das práticas de gestão do conhecimento de recursos humanos em uma clínica
}

\section{de imagem}

\author{
Analysis of human resource knowledge management practices in an image clinic \\ Análisis de las prácticas de gestión del conocimiento de recursos humanos en una clínica de \\ imágenes
}

Recebido: 22/07/2021 | Revisado: 29/07/2021 | Aceito: 10/08/2021 | Publicado: 14/08/2021

Lidiana Antonioli Dal Bem Pires

ORCID: https://orcid.org/0000-0001-8932-1932 Universidade Cesumar, Brasil

E-mail: lidianaantonioli@yahoo.com.br

Arthur Gualberto Bacelar da Cruz Urpia

ORCID: https://orcid.org/ 0000-0002-5273-6373

Universidade Cesumar, Brasil

E-mail: arthur.urpia@unicesumar.edu.br

Ely Mitie Massuda

ORCID: https://orcid.org/ 0000-0002-7485-5066

Universidade Cesumar, Brasil

E-mail: elymitie.m@gmail.com

\begin{abstract}
Resumo
$\mathrm{Na}$ 'Era da informação', as organizações passaram a implementar práticas de Gestão do Conhecimento (GC) para obterem vantagens competitivas. Diante disso, esta pesquisa objetivou diagnosticar o nível de implantação e de alcance das práticas de GC de Recursos Humanos em uma empresa do ramo de saúde que realiza exames de diagnóstico por imagem na cidade de Maringá (PR), Brasil. Metodologicamente, a pesquisa se caracteriza como um estudo de caso, com abordagens quantitativa e qualitativa. Para a coleta de dados foi aplicado um questionário desenvolvido pelo Instituto de Pesquisa Econômica Aplicada (IPEA) e foi também realizada uma análise documental. Como resultado, observou-se que o nível efetivo de implantação e o nível de amplitude do alcance das práticas de GC de Recursos Humanos foram altos e que apenas a prática Educação Corporativa está sendo utilizada abaixo de suas potencialidades. Com isto, algumas ações foram sugeridas a fim de consolidar as práticas estudadas.
\end{abstract}

Palavras-chave: Saúde; Gestão do conhecimento; Práticas de gestão do conhecimento.

\begin{abstract}
In the 'Information Age', organizations began to implement knowledge management (KM) practices to gain competitive advantage. Therefore, this research aimed to diagnose the level of implantation and reach of the GC practices of Human Resources in a health care company that performs diagnostic imaging tests in the city of Maringá (PR), Brazil. Methodologically, the research is characterized as a case study, with quantitative and qualitative approaches. For data collection, a questionnaire developed by the Institute of Applied Economic Research (IPEA) was applied and a documentary analysis was also performed. As a result, it was observed that the effective level of implementation and the breadth of reach of the KM practices of human resources were high and that only Corporate Education practice is being used below its potential. With this, some actions were suggested in order to consolidate the practices studied.
\end{abstract}

Keywords: Health; Knowledge management; Practices of knowledge management.

\section{Resumen}

En la "era de la información", las organizaciones comenzaron a implementar prácticas de Gestión del Conocimiento (KM) para obtener ventajas competitivas. Ante esto, esta investigación tuvo como objetivo diagnosticar el nivel de implementación y el alcance de las prácticas de KM de Recursos Humanos en una empresa del sector de la salud que realiza exámenes de diagnóstico por imágenes en la ciudad de Maringá (PR), Brasil. Metodológicamente, la investigación se caracteriza como un estudio de caso, con enfoques cuantitativos y cualitativos. Para la recolección de datos, se aplicó un cuestionario desarrollado por el Instituto de Investigación Económica Aplicada (IPEA) y también se realizó un análisis documental. Como resultado, se observó que el nivel efectivo de implementación y el nivel de amplitud del alcance de las prácticas de KM de Recursos Humanos fueron altos y que solo la práctica de Educación Corporativa se está utilizando por debajo de su potencial. Con esto, se sugirieron algunas acciones para consolidar las prácticas estudiadas.

Palabras clave: Salud; Gestión del conocimiento; Prácticas de gestión del conocimiento. 


\section{Introdução}

Diversas mudanças sociais, econômicas e tecnológicas vêm ocorrendo nas últimas décadas, dando origem, a partir da década de 1990, ao período denominado de 'Era da informação e do conhecimento'. Nesta nova era, a informação e o conhecimento, que são ativos intangíveis, são vistos como fundamentais para a acumulação do capital. Isto por serem os insumos básicos para a criação de inovações tecnológicas. Desta forma, verifica-se uma mudança importante, pois são os ativos intangíveis que são considerados vitais para a obtenção de vantagens competitivas sustentáveis e para a acumulação do capital (Davenport \& Prussak). Com isto, as organizações passaram a implementar práticas e ferramentas de Gestão do Conhecimento (GC). A GC é entendida como um conjunto de métodos, conceitos e atividades para agregar valor ao capital intelectual e, com isso, atingir sua capacidade de criar, armazenar, recuperar, transferir e reutilizar o conhecimento organizacional (Dalkir, 2011, Souza \& Ferreira, 2021). Segundo Nascimento e Sousa Júnior (2019), a gestão do conhecimento e o capital intelectual são primordiais para a sustentabilidade das organizações na atualidade.

Quando implementado nas organizações, a GC tanto se torna responsável por pequenas modificações (ao promover: a informatização das empresas, o aperfeiçoamento dos postos de trabalhos e uma melhor repartição do setor produtivo), quanto adquire um caráter estratégico, pois melhora o convívio entre os colaboradores, torna o processo de obtenção e compartilhamento de informações mais eficiente e menos custoso, promove um melhor compartilhamento e armazenamento do conhecimento e contribui para a geração de inovações de produtos e processos.

Tendo-se em vista esses aspectos, o objetivo geral é diagnosticar o nível de GC de Recursos Humanos (RH) em uma empresa do ramo de saúde que realiza exames de diagnóstico por imagem na cidade de Maringá. As práticas de GC de Recursos Humanos colaboram para transferir, disseminar e compartilhar informação e conhecimento (Batista et al., 2007).

O presente trabalho se justifica pelas seguintes causas: por possibilitar conhecer o nível das práticas de GC de recursos humanos da empresa que realiza exames de imagem do município de Maringá para, posteriormente, identificar práticas que possam ser aplicadas com o intuito de consolidar processos de GC nessas instituições. A consolidação de práticas de GC nesta instituição será de grande relevância dada a natureza dos serviços que a empresa disponibiliza, algo que evidencia sua atribuição no bem-estar da população.

Este trabalho, além desta breve introdução, possui mais quatro seções. A segunda seção apresenta uma contextualização sobre a GC e sobre suas práticas de recursos humanos. A terceira seção apresenta todo o procedimento metodológico da pesquisa. A quarta seção realiza a exibição dos dados e análise dos resultados. Por fim, a quinta seção aponta as considerações finais.

\section{A gestão do conhecimento: conceitos e práticas de recursos humanos}

\subsection{A gestão do conhecimento}

A partir da década de 1970, o mundo capitalista passou a presenciar uma série de mudanças, que se deram em decorrência, principalmente, dos seguintes fatores: i) crise da OPEP (Organização dos Países Exportadores de Petróleo), em que os principais países exportadores de petróleo elevaram o preço do petróleo, ocasionando uma alta inflação de custos e contribuindo para a recessão econômica mundial; ii) crise do sistema monetário internacional, em que os EUA decretaram unilateralmente o fim do acordo de Bretton Woods1; iii) introdução das políticas neoliberais e iv) avanço da globalização e decadência do Fordismo.

Para Albagli (1999, p. 293):

As transformações operadas a partir da década de 1970 representaram um salto qualitativamente novo em relação a esse processo. Iniciava-se então o que se iria caracterizar como uma verdadeira revolução científico-tecnológica (ou 
Terceira Revolução Industrial), baseada no desenvolvimento de um conjunto de tecnologias genéricas e na adoção de novos formatos organizacionais, configurando um novo paradigma técnico-econômico.

A partir da década de 1970, portanto, passou-se a verificar no mundo capitalista uma série de mudanças, incluindo inovações sociais, tecnológicas, políticas e econômicas. Estas mudanças mudaram a forma de competição entre as empresas, que passou a ter a informação e conhecimento como ativos fundamentais para a obtenção de vantagens competitivas sustentáveis (Davenport \& Prussak, 1999). Diante desse cenário em que o conhecimento se tornou o principal pilar da atividade econômica e as Tecnologias de Informação e Comunicação (TIC) têm acelerado a criação de uma série de inovações, a Gestão do Conhecimento (GC) se torna vital para as organizações tanto públicas quanto privadas de forma que as práticas de gestão do conhecimento tornaram-se essenciais para a sustentação de vantagens competitivas duradouras das empresas (Zyrianoff et al., 2021).

O termo Gestão do Conhecimento (Knowledge Management) foi expresso pela primeira vez no Estados Unidos por Karl Wiig, em 1986. Em seguida, destaca-se o trabalho de Takeuchi e Nonaka, em 1987, no Japão, que objetivou compreender as pesquisas de Polanyi e aplicá-las nas organizações (Souza, 2014).

Brito e Bolson (2014) entendem que a GC pode ser definida como um processo no qual pode-se obter, gerenciar e compartilhar a experiência e especialização dos componentes de uma empresa, com o intuito de no tempo certo obter a melhor informação. Rodriguez (2011) explica que a GC pode ser conceituada como a habilidade que uma organização possui em criar o conhecimento e articular sua disseminação interna e absorvê-la em seus sistemas, produtos e serviços. Quando implementado nas organizações, a GC tanto se torna responsável por pequenas modificações (ao promover: a informatização das empresas, o aperfeiçoamento dos postos de trabalhos e uma melhor repartição do setor produtivo), quanto adquire um caráter estratégico, pois melhora o convívio entre os colaboradores, torna o processo de obtenção e compartilhamento de informações mais eficiente e menos custoso, promove um melhor compartilhamento e armazenamento do conhecimento e contribui para a geração de inovações de produtos e processos.

\subsection{Práticas relacionadas a gestão de recursos humanos}

As práticas atribuídas a Gestão de Recursos Humanos contribuem com a transferência, a disseminação e o compartilhamento de informações e conhecimento e, dessa forma, são fundamentais para articular o rompimento de oposição à prática de compartilhar o conhecimento dentro das empresas. O intuito dessas práticas voltadas à gestão de recursos humanos nada mais é do que direcionar o gestor a construir uma equipe com competência, e que a mesma possa contribuir de forma natural para a aprendizagem organizacional. Desse modo, visam facilitar a transferência, disseminação e compartilhamento da informação e conhecimento (URPIA et al, 2016).

Os Fóruns/ Listas de discussão são um tipo de prática que pode ser utilizada pelos indivíduos com o intuito de trocar informações sejam elas presencialmente ou virtualmente. Os fóruns/ listas de discussão dão oportunidades para compartilhamento de experiências, ideias, bem como as informações. Esses cooperam de um modo em geral com o aperfeiçoamento de processos, crescimento de competências e atividades organizacionais. Criar ocasiões e locais para os colaboradores informalmente, assim como realizar passeios provocados pela organização, geram oportunidades para 0 intercâmbio entre funcionários que não tiveram o ensejo de se comunicarem no expediente do trabalho (DAVENPORT; PRUSAK, 1999). Também pode ser denominado como a Feira do Conhecimento, que permite fazer a permuta do conhecimento com espontaneidade, englobando indivíduos sem julgamento prévio sobre quais pessoas devem falar com outras.

Os Fóruns são aplicativos direcionados para a utilização em rede, que devem ser disponibilizados na Internet ou Intranet, conforme um servidor "web" que sustente materiais dinâmicos sustentados em base de dados (REIS; MARTINS, 
2008). A prática do Fóruns/listas de discussão permite diversas vantagens, tais como: a geração de grupos e comunidades, endereçando mensagens a várias pessoas simultaneamente. A área acadêmica faz uso dessa prática entre estudantes e professores, principalmente escolas e universidades com cursos à distância, pois, para transmitir o conhecimento e avaliá-lo, faz-se necessário os fóruns por meio da web.

Comunidades de prática são grupos informais de pessoas unidas com objetivos em comum. Essas comunidades são organizadas ao ponto de pessoas externas ou internas poderem colaborar para a organização. Essa prática propicia condições para o compartilhamento de melhores práticas e para o acesso de especialistas. Silva (2008) alega que as Comunidades de Prática compreendem a participação das pessoas em uma atividade, em que todos os participantes possuem entendimento comum sobre o que é a prática e qual o significado para suas vidas e para a comunidade. Já Davenport e Prusak (1999) definem essa prática como grupos organizados geralmente compostos por funcionários que se comunicam entre eles, pois associam as mesmas práticas e objetivos de trabalho. Sendo assim, se for útil a partilha e permear por anos, este grupo poderá oficializar o arranjo, referir um nome de grupo e constituir um sistema regular de trocas.

Para Santos (2014, p. 75):

Entre os principais benefícios das comunidades de prática podemos citar o ambiente favorável e confiável para intercâmbio de informação entre os participantes, utilização da experiência e conhecimento coletivo, melhora relacionamento interpessoal estabelecendo redes pessoais de longo prazo.

Conforme os autores apontam, unem-se grupos de pessoas informalmente para transferir conhecimentos e, como consequência, há uma interação agradável dos participantes ao ponto de permanecer redes de pessoas por longos períodos.

Educação Corporativa coopera no desenvolvimento sistematizado e integrado ao plano organizacional, de modo a gerar competências e habilidades, além de proporcionar novos conhecimentos. Segundo Lytovchenko (2015), no atual processo de transição para a economia do conhecimento, a competitividade das empresas está atrelada à competência dos trabalhadores e, nesse cenário, a educação corporativa exerce o papel de inserir os trabalhadores nesse contexto.

Entende-se que esta prática inserida dentro da organização garante que a empresa respeite a educação continuada e os funcionários sejam integrantes do capital. Em relação ao objetivo da Educação Corporativa, Carvalho (2012) define como um ato de desenvolver e fortificar as competências organizacionais e o conhecimento por meio do aprendizado apoiado nas necessidades estratégicas da empresa. É importante também salientar que a prática da Educação Corporativa não é sinônimo de Universidades Corporativas.

Narrativas (Storytelling) é utilizada no ambiente de GC para expor assuntos complexos, além de comentar situações e comunicar lições que foram assimiladas. No contexto de GC, narrativa literalmente significa descrever uma história que o indivíduo possui, um conhecimento de extrema importância, e narrar a história de sua experiência para outras pessoas que desejam adquirir esse conhecimento (DALKIR, 2011). Davenport e Prusak (1999) afirmam que as pessoas aprendem melhor com as histórias. Para os autores, uma das melhores maneiras de codificar o conhecimento é por intermédio desta prática, pois, por meio dela, é possível integrar a experiência e estender a novas expectativas, além de ensinar e aprender coisas consideradas mais complexas sem perder a comunicação entre os indivíduos.

Coaching também é uma prática de gestão de desempenho semelhante com mentoring. A diferença é que este não participa na elaboração das atividades, contudo, participa no diálogo e acompanhamento, alinhando as estratégias.

Oliveira (2010, p. 200) define a prática de Coaching como:

O desenvolvimento do funcionário para fazer bem seu trabalho ou a situação em que um profissional experiente em dado trabalho orienta outro, ensinando-o, motivando-o, fazendo-o praticar o trabalho (ou partes específicas dele) e oferecendo-lhe feedback sobre seu desempenho. 
Ainda para Oliveira (2010) o termo inglês coach originou-se em meados do século 19, na figura de uma grande carruagem com quatro rodas arrastada por cavalos, contendo uma boleia para duas pessoas, sendo comum vê-la nos filmes de faroeste. $\mathrm{O}$ termo coach, que até então era uma carruagem, passou também a significar o condutor (o cocheiro). Ao longo do tempo, esse termo também foi tomado de posse nas universidades da Inglaterra e Estados Unidos, onde os monitores tinham por responsabilidade encaminhar os alunos nas práticas escolares e atividades voltadas a esporte.

\section{Metodologia}

Do ponto de vista metodológico, esta pesquisa pode ser classificada como de caráter descritivo, possuindo abordagens quantitativa e qualitativa (Pereira et al, 2018), e adota o procedimento técnico de estudo de caso (Yin, 2015). Para a sua concretização, inicialmente, foi realizado levantamentos bibliográficos e uma análise documental de registros da empresa.

Esta pesquisa englobou todas as sete unidades de clínicas de imagem e o escritório administrativo que pertencem à mesma empresa, localizada em Maringá, na região norte do Paraná. Todas as unidades situam-se no mesmo município e realizam os seguintes exames laboratoriais e de imagem: ultrassom, raio-x, tomografia e ressonância. Para este estudo, foram selecionados todos os 14 responsáveis pelos setores que correspondem aos serviços de imagem, o que significa que a pesquisa trabalhou com a população ou universo de gestores da empresa de Diagnóstico por Imagem e não como uma amostra. O Quadro 1 apresenta o perfil dos respondentes ao destacar os seus cargos e atividades exercidas.

Quadro 1 - Perfil dos respondentes.

\begin{tabular}{|c|c|}
\hline Cargo & Atividades exercidas \\
\hline Gestor Recursos Humanos & $\begin{array}{l}\text { Responsável por supervisionar os colaboradores do setor, além de exercer as } \\
\text { seguintes atividades: contratação, demissão, elaborar políticas de cargo e salários, } \\
\text { treinamentos. }\end{array}$ \\
\hline Gestor de agendamento de exames & $\begin{array}{l}\text { Supervisiona todas as unidades da empresa de Maringá em relação ao agendamento } \\
\text { local e via telefone dos exames. }\end{array}$ \\
\hline Gestor Financeiro & $\begin{array}{l}\text { Responsável por efetuar os pagamentos de todas as unidades e contas a receber } \\
\text { apenas dos pacientes particulares. }\end{array}$ \\
\hline Gestor Faturamento/ Contas a receber & $\begin{array}{l}\text { Responsável por coordenar o setor de faturamento dos serviços prestados aos } \\
\text { hospitais, clínicas e pacientes além de receber os pagamentos realizados pelos } \\
\text { convênios. }\end{array}$ \\
\hline Gestor de Compras e Manutenção & $\begin{array}{l}\text { Responsável por efetuar as compras desde materiais de escritório, limpeza à materiais } \\
\text { e medicamentos (o gestor não realiza compras de aparelhos de imagem e } \\
\text { laboratoriais), além de ser responsável por fazer manutenções gerais em todas as } \\
\text { unidades. }\end{array}$ \\
\hline Gestores do setor de Recepção & Responsáveis por supervisionar os colaboradores das áreas da recepção. \\
\hline Gestor da área técnica de Radiologia & $\begin{array}{l}\text { Responsável por efetuar compra de equipamentos de imagem e de executar } \\
\text { manutenções desses equipamentos. }\end{array}$ \\
\hline Gestor da área de enfermagem & $\begin{array}{l}\text { Supervisiona os técnicos e auxiliares de enfermagem em recepcionar e posicionar o } \\
\text { paciente na realização do exame. }\end{array}$ \\
\hline Gestor de Tecnologia da Informação & $\begin{array}{l}\text { Responsável pela manutenção e elaboração dos programas de softwares utilizados } \\
\text { nas unidades. }\end{array}$ \\
\hline Gestor de Administração Geral & $\begin{array}{l}\text { Responsável por gerenciar todas as unidades, principalmente nos assuntos pertinentes } \\
\text { à administração. }\end{array}$ \\
\hline Diretor & Médico e proprietário da empresa. \\
\hline
\end{tabular}

Fonte: Elaborado pelos autores através das informações coletadas na pesquisa. 
Para a coleta de dados, foi aplicado o questionário elaborado por Batista et al. (2007), do Instituto de Pesquisa Econômica Aplicada (IPEA), que foi adaptado para fins da presente pesquisa. O questionário possibilita a realização do diagnóstico do grau de alcance e do estágio de implantação das práticas de GC na empresa. Este questionário é constituído de três dimensões, que são: i) práticas de GC de Recursos Humanos; ii) práticas de GC de Processos Organizacionais; iii) práticas de GC de Base Tecnológica e Funcional. Diante do objetivo geral desta pesquisa, apenas à primeira dimensão foi utilizada. Esta dimensão é composta das seguintes práticas: Comunidades de Prática, Coaching, Fóruns, Educação Corporativa e Narrativas

Para averiguar o estágio de implantação das práticas de GC a seguinte escala foi utilizada: [0] Não existem planos para implementação da prática; [1] Existem ações planejadas para a implementação da prática no futuro; [2] A prática está em processo de implementação; [3] A prática já está implantada; [4] A prática já está implantada e apresenta resultados importantes e relevantes para a organização. Para analisar o nível de alcance das práticas de GC considerou-se a seguinte escala: [1] Poucas iniciativas isoladas dentro da organização; [2] Alguns departamentos usam a prática; [3] Muitos departamentos usam a prática; [4] Amplamente disseminada na organização.

Vale ressaltar que para análise do resultado em relação ao nível efetivo de implantação das práticas e ferramentas selecionadas, foram analisadas apenas as respostas relacionadas aos níveis 3 (a prática já está implantada) e 4 (a prática já está implantada e apresenta resultados importantes e relevantes para a organização). Os demais níveis contribuíram para apurar a intenção da empresa em implementar as práticas futuramente (nível 1), se as práticas já estão em processo de implementação (nível 2), ou não há existência de planos para implantação das práticas (nível 0).

Em relação à análise dos resultados a respeito do nível de amplitude do alcance das práticas e ferramentas selecionadas, foram analisadas também apenas as respostas relacionadas aos níveis 3 (muitos departamentos usam a prática) e 4 (amplamente disseminada na organização) da escala do estágio do alcance, tendo-se em vista que apenas as respostas desses dois níveis indicam um amplo alcance das práticas e ferramentas. Os níveis 1 e 2 contribuíram para averiguar se há poucas iniciativas isoladas dentro da organização (nível 1) ou se a prática é utilizada apenas por poucos departamentos (nível 2).

Diante disso, para analisar o nível efetivo de implantação e nível de amplitude do alcance das práticas e ferramentas tal escala foi elaborada com os parâmetros sendo criados de forma arbitrária (Quadro 2).

Quadro 2 - Escala para análise dos resultados relativos ao nível efetivo de Implantação e estágio de amplitude do Alcance das práticas de GC.

\begin{tabular}{|c|c|}
\hline Nível Efetivo de Implantação e de amplitude do Alcance & $\mathbf{3 + 4}$ \\
\hline Nível baixo & Entre 0 a 39\% \\
\hline Nível médio & Entre 40\% a 60\% \\
\hline Nível alto & Acima de 60\% \\
\hline
\end{tabular}

Fonte: Elaborado pelos autores.

Para tabular os resultados do questionário, foi utilizado o Programa Microsoft Excel (2010). Em seguida, análise dos dados se deu por meio de técnicas estatísticas. Com a finalidade de averiguar a confiabilidade dos dados obtidos pelo questionário calculou-se o coeficiente alfa de Cronbach, que consiste em um método estatístico, que foi apresentado por Lee J. Cronbach em 1951, para medir a confiabilidade dos dados obtidos pela aplicação de questionários (HORA et al., 2010). Ainda para Hora et al (2010), o alfa visa medir a correlação entre as respostas em um questionário por meio da análise do perfil das respostas relatadas pelos respondentes. Abaixo, pode-se verificar a equação para o cálculo do coeficiente alfa: 


$$
\alpha=\left(\frac{k}{k-1}\right) \times\left(1-\frac{\sum_{i=1}^{k} s_{i}^{2}}{s_{t}^{2}}\right)
$$

Tem-se para os elementos da equação, a seguinte definição: $k$ : Número de itens/perguntas do questionário; $s_{i=}^{2}$ variância de cada item; e $s_{t}^{2}$; total das variâncias dos respondentes. Os valores apurados em $\alpha$ podem variar entre 0 e 1 , sendo que quanto mais próximo de 1, a confiabilidade torna-se maior entre os indicadores (MATTHIENSEN, 2011).

O Quadro 3 apresenta a escala adotada para análise da qualificação da consistência dos dados, conforme o alfa de Cronbach.

Quadro 3 - Qualificação da consistência, de acordo com o Alfa de Cronbach.

\begin{tabular}{|c|c|}
\hline Intervalo & Consistência \\
\hline$\alpha<0,6$ & Fraca \\
\hline $0,6 \leq \alpha<0,7$ & Moderada \\
\hline $0,7 \leq \alpha<0,8$ & Boa \\
\hline $0,8 \leq \alpha<0,9$ & Muito Boa \\
\hline$\alpha \geq 0,9$ & Excelente \\
\hline
\end{tabular}

Fonte: Elaborado pelos autores com base em Loesch e Hoeltgebaum (2012).

Verifica-se, conforme o Quadro 3, que para um alfa ser no mínimo satisfatório, ele deve apresentar um valor de 0,7. Os dados foram coletados entre os períodos de outubro de 2016 a fevereiro de 2017 através de visitas, aplicação de questionário, além da plataforma Whatsapp.

\section{Resultados e Discussão}

\subsection{Alfa de Cronbach}

A fim de medir a confiabilidade e consistência dos dados provenientes desta pesquisa, fez-se necessário utilizar o coeficiente alfa de Cronbach. Para efetivação da análise de consistência foi realizada a tabulação dos dados de dezoito práticas contidas no instrumento de diagnóstico do IPEA e, em seguida, transformadas em itens de uma planilha. Contudo, para a presente pesquisa, selecionaram-se práticas que pertencem a categoria de recursos humanos.

O valor do alfa de Cronbach para os dezoito itens que representam o nível de implantação de todas as práticas englobadas no instrumento de diagnóstico do IPEA foi de 0,8814 , sendo considerado um nível de consistência ótimo de acordo com a escala de Loeshi e Hoeltgebaum (2012). Já o valor do alfa de Cronbach para os dezoito itens que representam o nível de alcance foi de 0,8872. De acordo com a escala de Loeshi e Hoeltgebaum (2012), esse valor encontrado caracteriza também um nível de consistência ótimo. Diante dos valores dos alfas de Cronbach encontrados e dado que o instrumento de diagnóstico utilizado foi validado em diversos trabalhos, conclui-se que a pesquisa apresenta uma grande robustez.

\subsection{Resultado da análise do diagnóstico e análise documental}

Nessa subseção são apresentados os resultados obtidos com o diagnóstico referente às práticas de GC de recursos humanos, no que diz respeito aos níveis efetivos de implantação, níveis de amplitude do alcance e análise integrada desses níveis; além da análise documental, conforme Tabela 1. 
Tabela 1- Nível efetivo de Implantação das práticas de GC de RH.

\begin{tabular}{|c|c|c|c|c|c|c|}
\hline \multirow[b]{2}{*}{ PRÁTICA } & \multicolumn{6}{|c|}{ ESTÁGIO DE IMPLANTAÇÃO } \\
\hline & 0 & 1 & 2 & 3 & 4 & $\mathrm{~N} / \mathrm{R}$ \\
\hline Comunidades de prática & $0 \%$ & $0 \%$ & $14 \%$ & $7 \%$ & $79 \%$ & $0 \%$ \\
\hline Coaching & $0 \%$ & $0 \%$ & $21 \%$ & $43 \%$ & $36 \%$ & $0 \%$ \\
\hline Fóruns & $0 \%$ & $0 \%$ & $21 \%$ & $50 \%$ & $29 \%$ & $0 \%$ \\
\hline Educação corporativa & $43 \%$ & $14 \%$ & $21 \%$ & $0 \%$ & $21 \%$ & $0 \%$ \\
\hline Narrativas & $7 \%$ & $7 \%$ & $7 \%$ & $7 \%$ & $71 \%$ & $0 \%$ \\
\hline Médias & $10 \%$ & $4 \%$ & $17 \%$ & $21 \%$ & $47 \%$ & $0 \%$ \\
\hline
\end{tabular}

Legenda: 0 - não existem planos de implantação; 1 - planejada para o futuro; 2 - em processo de implantação; 3 - já está implantada; 4 implantada e apresentando resultados relevantes, e; n/r - não responderam.

Fonte: Elaborado pelos autores a partir dos resultados obtidos na pesquisa.

Referente à Tabela 1, percebe-se pela análise das médias que, de forma geral, as práticas de RH abordados na pesquisa possuem o nível efetivo de implantação alto, pois $69 \%$ dos gestores da empresa Clínica de Diagnóstico por Imagem responderam que estas práticas de GC estão implementadas entre os níveis 3 (a prática já está implantada) e 4 (a prática já está implantada e apresenta resultados importantes e relevantes para a organização) em sua empresa. Dentre os demais $31 \%$ dos gestores restantes, 17\% apontaram que há práticas de GC em processos de implementação (nível 2); 4\% afirmaram existir planos futuros de implementação das práticas de GC de RH (nível 1); e 10\% alegaram que não há sequer planos de implementação destas práticas (nível 0).

$\mathrm{Na}$ análise individual de cada prática, quase todas apresentaram nível efetivo de implantação alto (soma dos níveis 3 e 4) pela percepção dos gestores: Coaching, Fóruns e Narrativas, (79\%); Comunidades de Prática (86\%). A prática Educação Corporativa $(21 \%)$ foi a única que apresentou nível efetivo de implantação baixo.

Na Figura 1 apresentam-se os resultados quanto ao nível efetivo de implantação das práticas de GC de recursos humanos.

Figura 1 - Nível efetivo de implementação das práticas de GC de RH.

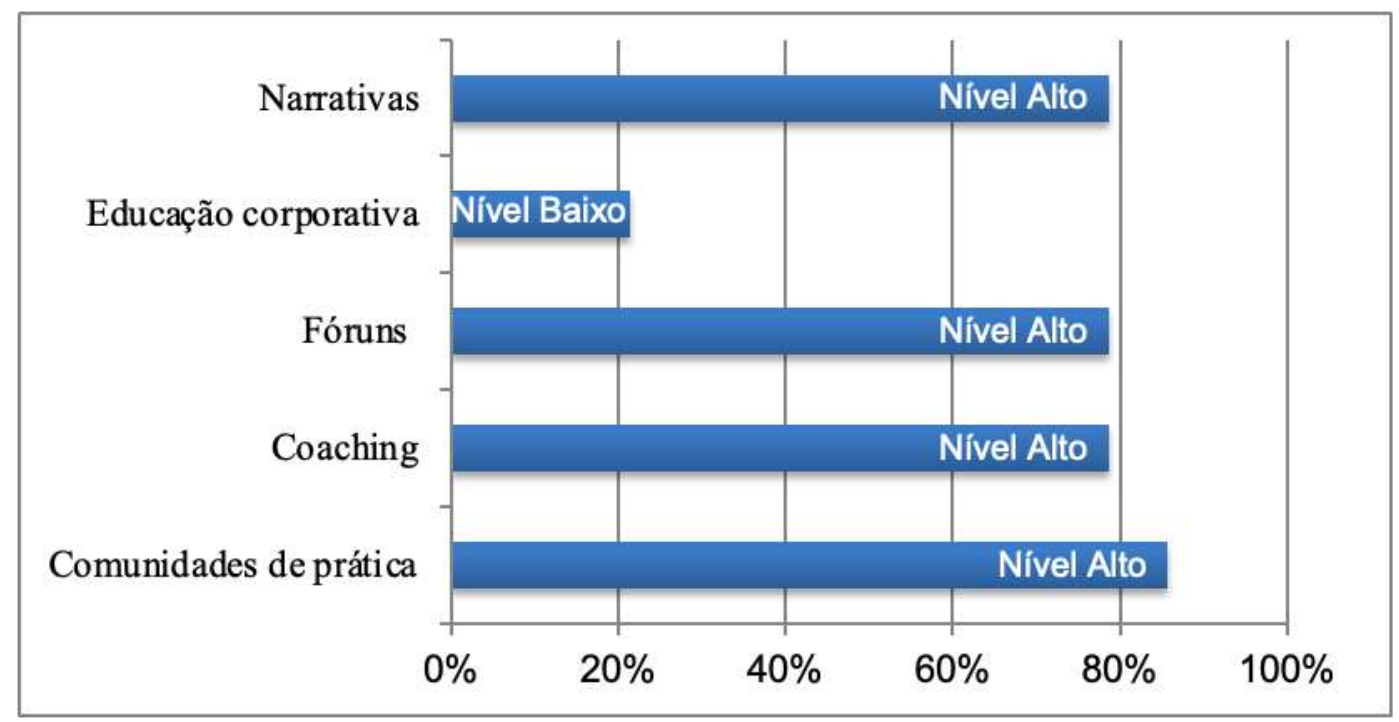

Legenda: 0 - não existem planos de implantação; 1 - planejada para o futuro; 2 - em processo de implantação; 3 - já está implantada; 4 implantada e apresentando resultados relevantes, e; $\mathrm{n} / \mathrm{r}$ - não responderam.

Fonte: Elaborado pelos autores a partir dos resultados obtidos na pesquisa. 
Quanto ao nível de amplitude do alcance, registram-se na Tabela 2 os resultados das práticas de GC em relação ao seu uso na empresa Clínica de Diagnóstico por Imagem.

Tabela 2 - Nível de Amplitude do Alcance das práticas de GC de RH.

\begin{tabular}{l|c|c|c|c|c|}
\hline \multirow{2}{*}{\multicolumn{1}{c|}{ PRÁtICA }} & \multicolumn{5}{c}{ Alcance } \\
\cline { 2 - 6 } & 1 & 2 & 3 & 4 & N/R \\
\hline Comunidades de prática/comunidades de conhecimento & $0 \%$ & $0 \%$ & $71 \%$ & $29 \%$ & $0,0 \%$ \\
\hline Coaching & $0 \%$ & $43 \%$ & $36 \%$ & $21 \%$ & $0,0 \%$ \\
\hline Fóruns (presenciais e virtuais//istas de discussão & $0 \%$ & $7 \%$ & $57 \%$ & $36 \%$ & $0,0 \%$ \\
\hline Educação corporativa & $64 \%$ & $14 \%$ & $0 \%$ & $21 \%$ & $0,0 \%$ \\
\hline Narrativas & $7 \%$ & $14 \%$ & $14 \%$ & $64 \%$ & $0,0 \%$ \\
\hline \multicolumn{1}{c|}{ Médias } & $14 \%$ & $16 \%$ & $36 \%$ & $34 \%$ & $0 \%$ \\
\hline
\end{tabular}

Legenda: 1 - poucas iniciativas isoladas; 2 - restrito a alguns departamentos; 3 - muitos departamentos usam a prática; 4 - amplamente disseminada na organização; e N/r - não responderam.

Fonte: Elaborado pelos autores a partir dos resultados obtidos na pesquisa.

Pela Tabela 2, percebe-se pela análise das médias que, de forma geral, as práticas de RH abordados na pesquisa possuem o nível de amplitude do alcance alto, pois 70\% dos gestores acreditam que estas práticas de GC estão implementadas entre os níveis 3 (a prática já está implantada) e níveis 4 (a prática já está implantada e apresenta resultados importantes e relevantes para a organização) em sua empresa Clínica de Diagnóstico por Imagem. Dentre os 30\% dos gestores restantes, 16\% dos gestores alegaram que as práticas se encontram no nível 2 de amplitude do alcance, ou seja, apenas alguns departamentos fazem uso das práticas, e $14 \%$ dos gestores afirmaram que existem poucas iniciativas isoladas dentro da empresa, ou seja, nível 1 de amplitude do alcance.

As práticas apresentadas com nível de amplitude do alcance alto (soma dos níveis 3 e 4), conforme a percepção dos gestores, foram as seguintes: as práticas Comunidades de Prática (100\%), Fóruns (93\%) e Narrativas (79\%). A prática Coaching apresentou nível médio (57\%), enquanto a prática Educação Corporativa apresentou nível baixo de amplitude do alcance $(21 \%)$.

Por meio doa Figura 2, demonstra-se, de forma geral, o nível de amplitude do alcance das práticas de RH, de acordo com a percepção dos gestores. 
Figura 2 - Nível de amplitude do alcance das práticas de GC de RH.

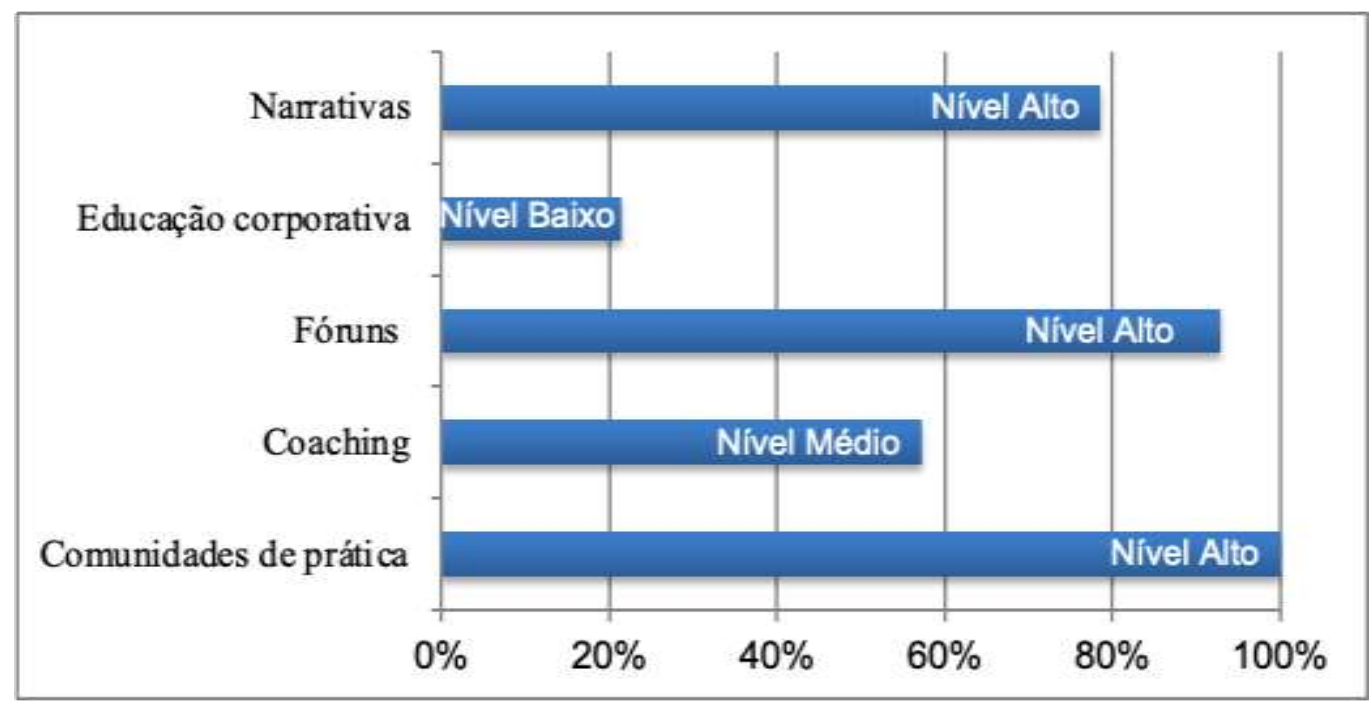

Legenda: 1 - poucas iniciativas isoladas; 2 - restrito a alguns departamentos; 3 - muitos departamentos usam a prática; 4 - amplamente disseminada na organização; e $\mathrm{N} / \mathrm{r}$ - não responderam.

Fonte: Elaborado pelos autores a partir dos resultados obtidos na pesquisa.

Para melhor compreensão sob os níveis efetivos de implementação (níveis 3 e 4) e os níveis de amplitude do alcance (soma dos níveis 3 e 4) das práticas de GC voltadas a RH, é demonstrado por meio da Figura 3 uma análise mais detalhada referente ao resultado integrado dessas práticas. De forma geral, observa-se que os níveis de amplitude do alcance das práticas de GC de RH acompanham os níveis efetivos de implantação. Logo, percebe-se que essas práticas em geral estão sendo utilizadas na empresa Clínica de Diagnóstico por Imagem dentro de suas potencialidades.

Figura 3 - Percepção Integrada acerca do nível de implantação e alcance das práticas de GC de RH.

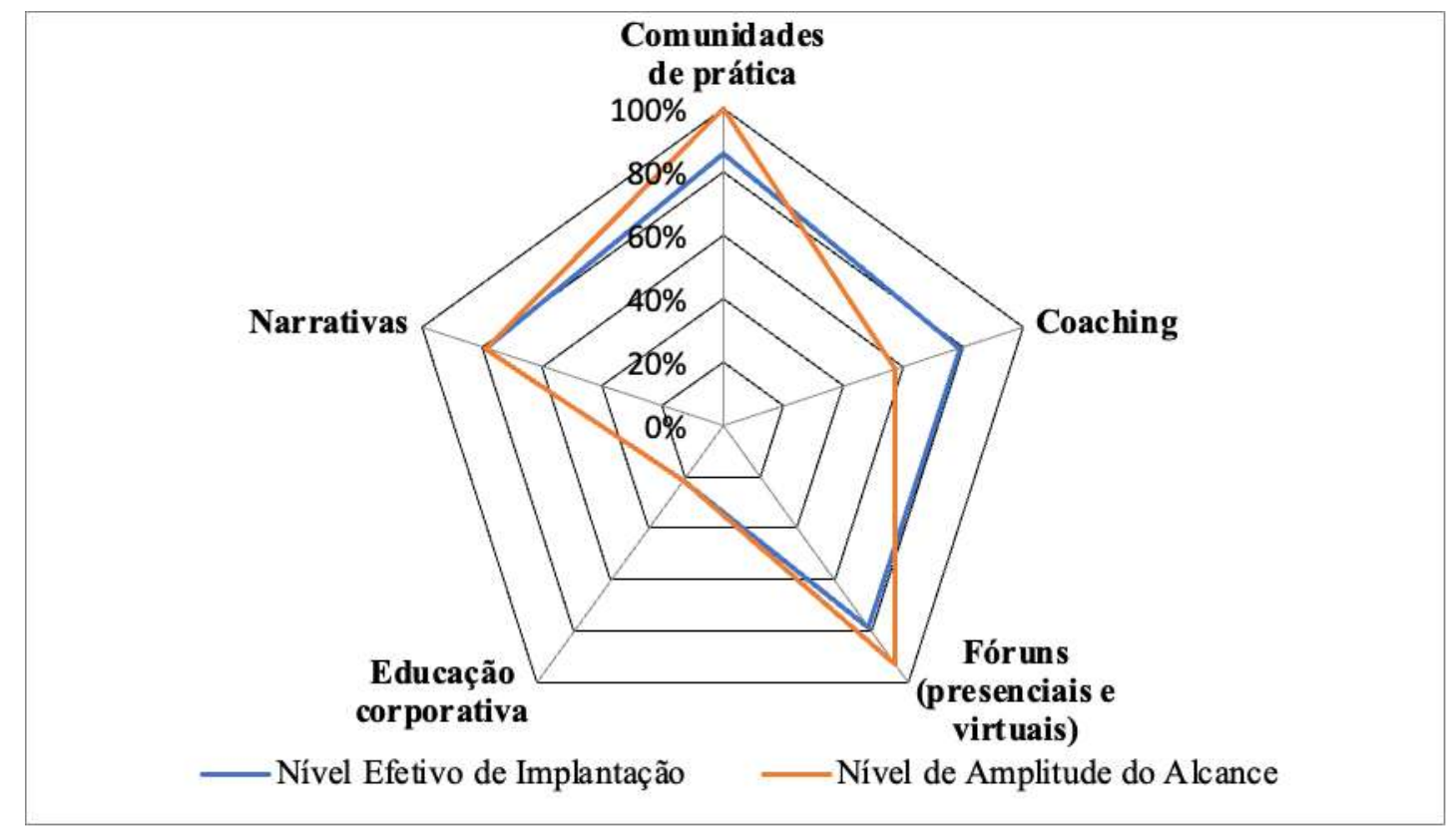

Fonte: Elaborado pelos autores a partir dos resultados obtidos na pesquisa.

Ainda pela Figura 3, observa-se que a prática Comunidades de Prática possui 100\% de amplitude do alcance dentro da empresa, o que pode gerar benefícios, tais como: melhora o convívio entre os indivíduos e dessa forma estimula redes pessoais 
a longo prazo; incentiva e acelera a troca de informações, isto por possibilitar um ambiente propício; contribui para a socialização do conhecimento, que é a fase de sua conversão onde o colaborador pode compartilhar seu conhecimento tácito diretamente com outros colaboradores da instituição, fazendo com que o mesmo se torne coletivo entre a equipe; propicia condições para a transferência de melhores práticas e também para o acesso de especialistas.

Através da análise documental realizada, identificou-se que a prática Comunidades de Prática é realizada através de um aplicativo denominado de Spark. Este aplicativo é utilizado pelos colaboradores e instalado nos computadores, sendo administrado por um servidor onde ficam hospedados as conversas e acessos de usuários. Como pode-se avaliar, é uma prática que apresenta excelente resultado além de ser um recurso gratuito, não havendo necessidade de investimento para adquiri-lo.

A utilização da prática Fóruns dentro de suas potencialidades, tal como pode ser visualizado no Gráfico 3, pode promover vários benefícios para empresa Clínica de Diagnóstico por Imagem, tais como: a troca de ideias, compartilhamento de informações e experiências, podendo os colaboradores expor suas concepções de forma informal sem que os mesmos se sintam constrangidos; a geração de grupos e comunidades, endereçando mensagens a várias pessoas simultaneamente, algo que simplifica e agiliza a comunicação; além de cooperar de um modo em geral com o aperfeiçoamento de processos, crescimento de competências e atividades organizacionais, contribuindo para melhoria de processos na prestação de serviços. Segundo dados e informações coletados nas unidades da empresa Clínica de Diagnóstico por Imagem pesquisadas, são realizadas, uma vez por mês, reuniões informais para discutir estratégias para solucionar problemas e para melhorias no atendimento, seja no setor de recepção ou no setor de realização de exames.

Em relação à prática Narrativas, que também está sendo utilizada dentro de suas potencialidades, os benefícios gerados são os seguintes: resolução de problemas, isto por facilitar o diálogo entre as partes; contribui para que os colaboradores da empresa Clínica de Diagnóstico por Imagem possam relatar assuntos complexos para outros colaboradores e até mesmo para os clientes, melhorando a forma de comunicação entre todos; facilita os processos de mudanças culturais na empresa analisada, isto por facilitar que o gestor explique quais mudanças serão geradas.

Ao tabular os dados do questionário em relação à prática Coaching, observa-se que 79\% dos gestores consideraram que a prática está implantada e que pode apresentar resultados importantes e relevantes, mas quando é analisado o alcance, apenas 36\% dos gestores responderam que muitos departamentos da empresa Clínica de Diagnóstico por Imagem utilizam essa prática e $21 \%$ dos gestores responderam que a prática está amplamente disseminada. Diante disso, o nível de amplitude do alcance é considerado médio, o que indica que não está havendo um aproveitamento qualitativo das totais potencialidades do Coaching, dificultando assim o monitoramento em que o gestor realiza referente ao desempenho das atividades dos colaboradores; o relacionamento entre gestores e colaboradores, principalmente em situações que requer auxílio. Portanto, de forma geral, o uso da prática de Coaching abaixo das suas potencialidades atrapalha a gestão de desempenho por parte da empresa analisada.

A prática Educação Corporativa foi a única que apresentou nível efetivo de implantação baixo e também nível de amplitude do alcance baixo. Logo, essa prática está sendo utilizada abaixo de sua potencialidade. Por atingir esses níveis baixos, as seguintes implicações são possíveis: a equipe poderá ficar desatualizada em processos para operar em equipamentos, administração e recepção e, com isso, perder espaço para outras clínicas de imagem concorrentes; além do mais, deixar de reduzir tempo para resolução de problemas. Contudo, vale ressaltar que no momento que houve a aplicação dos questionários aos gestores, os mesmos relataram que foram realizados alguns treinamentos, tais como: treinamento de primeiros socorros, treinamento de informática e treinamento de ética. 


\section{Considerações Finais}

O objetivo geral proposto para esse estudo foi diagnosticar o nível de implantação e de alcance de práticas de GC de recursos humanos em uma empresa do ramo de saúde que realiza exames de diagnóstico por imagem no município de Maringá (PR). Para tal, inicialmente foi calculado o coeficiente Alfa de Cronbach, cujo valor encontrado foi excelente tanto para o nível de implementação quanto para o nível de alcance das práticas de GC contidas no questionário, permitindo deduzir que há confiabilidade nos dados obtidos pela aplicação do questionário.

Em seguida, foi realizada a análise dos dados obtidos pelo diagnóstico. O resultado do diagnóstico demonstrou que as práticas de GC de RH apresentaram um nível efetivo de implantação alto, pois, na média, 69\% dos gestores consideraram que essa categoria se encontra entre o nível 3 (a prática já está implantada) e 4 (a prática já está implantada e apresenta resultados importantes e relevantes para a organização). Dentre as práticas desta categoria, apenas Educação Corporativa apresentou um nível efetivo de implantação baixo. Todas as demais práticas apresentaram um nível efetivo de implantação alto.

O nível de amplitude do Alcance para essa categoria também é considerado alto, tendo-se em vista que, na média, 70\% dos gestores responderam que as práticas permeiam entre o nível 3 (muitos departamentos usam a prática) e nível 4 (amplamente disseminada na organização) na empresa Clínica de Diagnóstico por Imagem. Das práticas desta categoria, Educação Corporativa apresentou um nível de amplitude do Alcance baixo, o Coaching médio e as demais práticas um nível alto.

Desta forma, a prática Educação Corporativa foi diagnosticada apresentando tanto um nível efetivo de implantação quanto um nível de amplitude do Alcance baixo. Isto pode provocar determinadas implicações para a empresa, que foram apresentadas na seção acima. Diante destas implicações, sugere-se que determinadas ações sejam realizadas pela empresa Clínica de Diagnóstico por Imagem a fim de consolidar ainda mais os processos de GC. Dentre as ações, propõe-se que a empresa analisada realize parcerias com Universidades, com a Secretaria de Saúde de Maringá e com o Ministério da Saúde, a fim de realizar cursos e treinamentos para que os seus colaboradores possam disseminar o conhecimento e, consequentemente, melhorar o processo decisório. Neste sentido, faz-se importante lembrar que o Ministério da Saúde disponibiliza diversos cursos gratuitos em diversos níveis acadêmicos, respeitando as necessidades de educação e capacitação permanente dos funcionários do ramo da saúde, utilizando até da modalidade da educação à distância.

Faz-se importante destacar que para a elaboração desta pesquisa foi necessário lidar com algumas limitações e barreiras que surgiram ao longo do processo. Umas das principais dificuldades enfrentadas foi com a não permissão para se obter acesso a dados estratégicos da empresa pesquisada, bem como acesso a informações específicas de alguns setores.

Como desdobramento futuros, pretende-se escrever um relatório para entregar para essa empresa, a fim de ajudá-las a consolidar a GC em suas organizações. Pretende-se também dar continuidade a essa pesquisa, aplicando o mesmo instrumento de diagnóstico em outras organizações desse ramo, uma vez que a GC é um tema ainda pouco explorado nestas organizações no município de Maringá. Sugere-se a aplicação do diagnóstico em outras organizações do ramo de saúde para a elaboração de análises comparativas, com os dados obtidos nesta pesquisa para futuros trabalhos.

\section{Referências}

Albagli, S. (1999). Novos Espaços de Regulação na Era da Informação e do Conhecimento. In: Lastres, H. M. M.; Albagli, S. Informação e Globalização na Era do Conhecimento. (Cap. 11. pp.290-313). Rio de Janeiro: Campus.

Batista, F. F., Xavier, A. C. da R., Mendes, L. C.\& Rosemberg, G. (2007). GC em Organizações Públicas de Saúde. Texto para Discussão, no 1316. Brasília: IPEA. https://www.ipea.gov.br/portal/index.php?option=com_content\&view=article\&id=4559

Bento, J. de C, Massuda, E. M., Urpia, A. G. B. da C. \& Bortolozzi, F. (2016). Práticas da gestão do conhecimento em recursos humanos em instituição de ensino superior à distância. Espacios, (37) 21. https://www.revistaespacios.com/a16v37n29/16372921.html 
Research, Society and Development, v. 10, n. 10, e385101018587, 2021

(CC BY 4.0) | ISSN 2525-3409 | DOI: http://dx.doi.org/10.33448/rsd-v10i10.18587

Brito, L. M. P., \& Bolson, S. B. (2014). Gestão do Conhecimento: estudo em uma Instituição Privada de Ensino Superior. RAUnP - Revista Eletrônica do Mestrado Profissional em Administração da Universidade Potiguar, 6(2), 77-87. http://www.spell.org.br/documentos/ver/32664/gestao-do-conhecimento-estudo-em-uma-instituicao-privada-de-ensino-superior/i/pt-br

Carvalho, C. A. (2012). Gestão do Conhecimento. $5^{\text {a }}$ ed. São Paulo: Pearson.

Dalkir, K. (2011). Knowledge Management in Theory and Practice. Burlington: Elsevier, 2011.

Davenport, T. H. \& Prusak, L. (1999). Conhecimento Empresarial: como as organizações gerenciam seu capital intelectual. Rio de Janeiro: Campus.

Hora, H. R. da, Monteiro, G. T. R. \& Arica, J. (2010). Confiabilidade em Questionários para Qualidade: Um Estudo com o Coeficiente Alfa de Cronbach. Produto \&Produção. (11) 2, 85-103. DOI: https://doi.org/10.22456/1983-8026.9321

Loesch, C. \& Hoeltgbaum, M. (2012). Métodos Estatísticos Multivariados. São Paulo: Saraiva.

Lytovchenko, I. (2015) Origins and formation of corporate education in the USA. Comparative Professional Pedagogy, (5) 3, 53-57. https://www.researchgate.net/publication/307654985_Origins_and_Formation_of_Corporate_Education_in_the_USA.

Matthiensen, A. (2011). Uso do Coeficiente Alfa de Cronbach em Avaliações por Questionários. Embrapa. Roraima: Boa Vista.

Nascimento, L. da S. \& Sousa Júnior, J. H. de. (2019). Relacionando Capital Intelectual, Gestão do Conhecimento e Sustentabilidade: um modelo conceitual. Navus. Revista de Gestão e Tecnologia. (9) 2, 92-104. https://doi.org/10.22279/navus.2019.v9n2.p92-104.867

Oliveira, M. A. (2010). Comportamento Organizacional para a Gestão de Pessoas: Como agem as empresas e seus gestores. São Paulo: Saraiva.

Pereira A. S. et al. (2018). Metodologia da pesquisa científica. [free e-book]. Santa Maria/RS. Ed. UAB/NTE/UFSM. 5.3) Koche, J. C. (2011). Fundamentos de metodologia científica. Petrópolis: Vozes. https://repositorio.ufsm.br/bitstream/handle/1/15824/Lic_Computacao_Metodologia-PesquisaCientifica.pdf?sequence $=1$

Reis, F. L. dos \& Martins, A. E. (2008). A importância dos Fóruns de Debate na Comunicação e Interação no Ensino Online. Revista de Estudos da Comunicação. v. (09), 19, 97-111, 2008. http://www2.pucpr.br/reol/pb/index.php/comunicacao?dd99=issue\&dd0=143

Rodriguez, M. V. R. (2011). Gestão do Conhecimento e Inovação nas Empresas. Rio de Janeiro: Qualitymark.

Santos, G. T. dos. (2014). Método para captura de lições aprendidas: em direção a melhoria contínua na Gestão de Projetos. Revista de Gestão e Projetos. (5) 1,71-83. DOI: https://doi.org/10.5585/gep.v5i1.250

Silva, H. de F. N. (2014). O Processo de Criação de Conhecimento Organizacional em Comunidades de Prática. In: Angeloni, M. T. (Org.). Gestão do Conhecimento no Brasil. (Cap. 3). Rio de Janeiro: Gespública.

Sousa, M. A. B. (2014). Gestão do Conhecimento: Uma Contribuição ao seu entendimento. Revista de Administração e Negócios da Amazônia (6) 3, 38-47. DOI: http://dx.doi.org/10.18361/2176-8366/rara.v6n3p38-47

Sousa, S., \& Ferreira, A. (2021). Capital intelectual: revisão de literatura. Gestão E Desenvolvimento, (29), 245-259. DOI: https://doi.org/10.34632/gestaoedesenvolvimento.

Yin, R.K. (2015). O estudo de caso. Porto Alegre: Bookman.

Zyrianoff, W., Kuniyoshi, M. S., Gaspar, M. A. \& Nascimento, H. do. (2021). Práticas de Gestão do Conhecimento e Capacidade Absortiva Aplicadas à Melhoria de Desempenho e Qualidade na Manutenção Industrial. Reserch, Society and Development. (10) 2, DOI: https://doi.org/10.33448/rsd-v10i2.12713 